\title{
Los murales de la UNAN-Managua. Lugar de permanente batallas por la memoria
}

Luis Javier Gaitán Lugo. Universidad Nacional Autónoma de Nicaragua-Managua, Dpto. de Historia

lgaitanlugo@yahoo.com

\begin{abstract}
RESUMEN
El presente ensayo tiene por objetivo analizar la memoria histórica institucional de la UNAN-Managua manifestada en los distintos murales que en ella se encuentran y sus vinculaciones con la sociedad de hoy. Como el título expresa, se centra la atención en la elaboración de pintas a lo interno de la Institución, las etapas de la elaboración de murales, y su significado en la actualidad. El estudio realizado parte de los presupuestos teóricos que brinda la Historia del Tiempo Presente y de manera particular la memoria histórica de la sociedad como problema de investigación. Aparte de los análisis teóricos, se llevaron a cabo dos entrevistas, asimismo, se hizo uso de la técnica fotográfica para dar respaldo a las ideas planteadas.

Palabras clave: Historia del Tiempo Presente, memoria histórica, batallas por la memoria, murales, represión.
\end{abstract}

\section{ABSTRACT}

This essay aims to analyze the institutional memory of the Unite-Managua manifested in different murals found therein and its links with society today. As the title says, the attention on the development of pints internally in the institution, the stages of development of murals, and its meaning today focuses. The study of the theoretical assumptions provided by the History of the Present Time and particularly the historical memory of the society as a research problem. Apart from the theoretical analysis, they conducted two interviews also made use of the photographic technique to give back to the ideas raised.

Keywords: History of the Present Time, historical memory, memory battles, murals, repression.

\section{INTRODUCCIÓN}

La Historia del Tiempo Presente se ha convertido durante las últimas décadas en objeto de interés y preocupación para los historiadores, sobre todo lo concerniente a la construcción de la(s) memoria(s) que subyacen en el sustrato mental de distintos sectores de la sociedad, y que en el mayor de los casos son utilizados por las diferentes esferas de poder político-económico para satisfacer intereses particulares. La necesidad del estudio de la memoria surge a partir de la falta de vínculos de la experiencia contemporánea individual y colectiva con las generaciones anteriores. Esta condición se asemeja a una tejedora que al amanecer deshila su trabajo de la noche anterior, volviendo al proceso de elaboración y construcción de su cotidianeidad. Igual pasa con la sociedad. 
En nuestro caso, no es suficiente conservar los vestigios materiales del pasado, de manera particular los murales del Recinto Universitario Rubén Darío -cuyas pintas versan acerca de la lucha guerrillera contra la dictadura Somocista, el triunfo de la Revolución Popular Sandinista, la defensa de la Revolución, la lucha del 6\% Constitucional, y otros referidos a personajes emblemáticos de la Universidad-, sino que se debe promover un análisis histórico de lo que significó y significa el contenido social de estas pinturas en la historia nacional e institucional. Los pueblos sin memoria propia tienden a ser recipientes de "memorias" arbitrarias a sus intereses.

Para el tema que nos ocupa hemos decidido retomar la definición de memoria colectiva como "una representación narrativa, es decir, un relato, que un grupo posee de un pasado que, para algunos de los miembros que lo integran, se extiende más allá del horizonte individual, un discurso narrativo que tiene como sujeto a dicho grupo y que intenta dar sentido a eventos o experiencias relevantes de su pasado”. (Antognazzi Comp., 2006: 21)

Del concepto anterior, es importante retomar ¿Qué sentido le damos a eventos o experiencias relevantes de nuestro pasado? ¿Qué sentido muestran los murales de la universidad respecto a esas experiencias relevantes? ¿Qué expresan? ¿Tienen alguna relación con nuestro presente? ¿De qué manera inciden en la construcción de la memoria colectiva de la sociedad y particularmente en la juventud estudiantil que a diario transita entre ellos?

De estas interrogantes, surgen las batallas por la memoria, de donde se extraen recuerdos, hechos, símbolos e imágenes; algunas veces sesgados en función de un interés determinado de un grupo social, partido político o sector financiero. Dichos referentes de memoria reflejan gran parte de los conflictos más relevantes de nuestro tiempo. De ahí, que sea necesario definir que son murales y cuál es su importancia como fuentes para el estudio de la historia. Por lo general son pinturas de gran tamaño, que se colocan o están hechas sobre la superficie de un muro o pared, cuyo contenido varía según el estado de ánimo y las circunstancias (contexto) en que se pinte.

Aterrizando en nuestro caso de estudio, las imágenes iconográficas -murales-, actúan como columnas vertebrales de la memoria de determinado sector de la sociedad. En este sentido, "son la expresión de lo que se quiere guardar, a la vez que sirven como eslabón gráfico, cuya función no sólo se limita a recrear sino a fundamentar las experiencias colectivas". (Rosenzviag, 1998, p. 95)

Y como lugares que guardan la memoria, su contenido es objeto del choque de intereses y choque con la memoria previa de la juventud, transmitida por la tradición oral y escrita, la 
historiografía, los medios de comunicación, el Estado, la familia etc., donde cada grupo de poder en pugna hace uso de ellos o los descalifica como mecanismos de legitimación y de cohesión social según convenga. Tal como lo planteaba, Meyer (1998), en todas estas fuentes subyace la carga ideológica, la intención política, y es aquí precisamente donde está la tarea irrenunciable de desconstruir la memoria individual y colectiva a fin de construir la historia. Los usos y abusos de la memoria, las formulaciones históricas a la manera de ideologías o falsas conciencias no pueden ser soslayadas.

\section{Parámetros y costos del quehacer muralístico en la UNAN-Managua. 1970 a la actualidad.}

Para continuar, debemos aclarar que no contamos con la fecha exacta en que dio inicio la producción de murales en la Universidad, pudo haber sido antes de la fecha indicada, pero guiados por el contenido de las pinturas y por las figuras que en ellas se recrean, se decidió dejarlo a partir de la década del setenta.

En sus inicios, los murales fueron de carácter espontáneo, es decir, que las autoridades universitarias no intervinieron en ellos, ni hubo necesidad de autorización por parte de las mismas. Antes bien, se dejaba a criterio de los estudiantes y maestros expresar su repudio al régimen político existente. En la década de los ochenta, continuó la misma situación; producto del estallido revolucionario la comunidad universitaria siguió con la libertad irrestricta para llevar a cabo sus pintas en las paredes y muros de la universidad.

Hasta hace algunos años, para la realización de los murales se solicitaba la debida autorización de la Administración General, el permiso es concedido siempre y cuando aquello que va a pintarse sea educativo, que posea calidad y que a la vez su contenido no choque o sea arbitrario con las normas básicas o lineamientos de la comunidad universitaria. Algunos murales pintados en el Recinto han sido promovidos por maestros, personal administrativo, estudiantes y a la vez militantes sandinistas; que quieren revivir o rescatar del olvido todos aquellos personajes que en su época tuvieron un papel significativo, y que actualmente se necesitan apreciar y recuperar sus valores morales e ideológicos, en aras de resolver los conflictos sociales de hoy. 


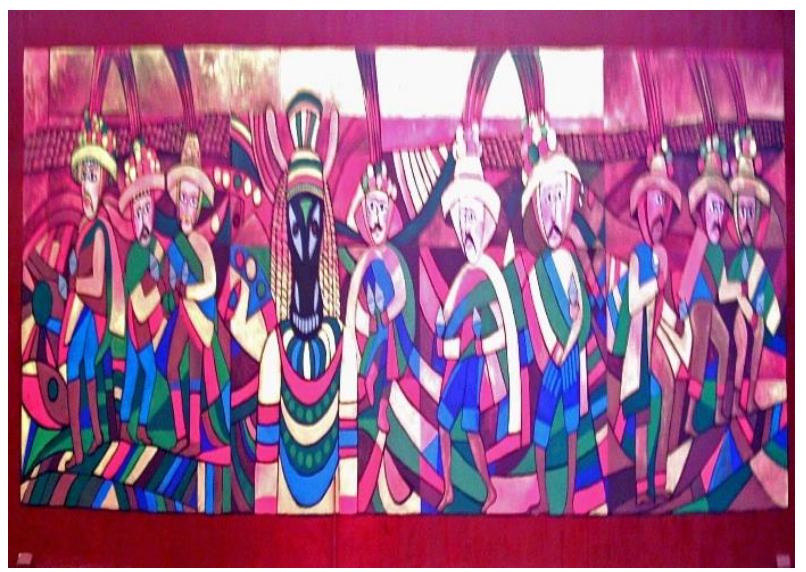

Desde hace unos años, la tónica del gasto de los murales, es que la Institución asume el costo completo, este fue el caso del mural referido a la obra teatral del Güegüense, cuyo precio se aproximó a los 15 mil córdobas. En años recientes, se han realizado murales de carácter institucional, donde la universidad ha asumido el pago de ellos, como el mural del Auditorio Roberto González, alusivo al Güegüense, propuesto por el Departamento de Cultura debido a que la obra fue declarada por la UNESCO, Patrimonio Intangible de la Humanidad, y también fue reconocido como Patrimonio Nacional por la Asamblea Legislativa. ${ }^{1}$

De igual forma, desde hace unos años, es común observar murales que se deterioran y nadie hace nada por conservarlos, al respecto el profesor Abel Garache -Director de Relaciones Internacionales de la UNAN-Managua- señaló en el año 2006, que "sólo el gremio estudiantil se ha preocupado por cuidar aquellos murales por los que se sienten representados como el dedicado a Marlon Zelaya; en cambio los gremios restantes no toman cartas en el asunto y sus murales se pierden en el tiempo, entre ellos los murales ofrendados a Santos Sovalbarro y Esperanza Monje." (Entrevista realizada por el equipo investigador al Msc. Abel Garache. 27 de noviembre, 2006).

Años atrás, los murales dedicados a Esperanza Monje y Santos Sovalbarro fueron restaurados a instancias del Departamento de Cultura, y del Sindicato de Trabajadores Docentes de la Universidad, mientras otros han caído en el deterioro en la actualidad.

\section{EI RURD, los murales, la historia y la memoria.}

Cada período electoral en Nicaragua, es expresión no sólo de intereses políticos, sino también de luchas por la memoria. Fue en las elecciones nacionales del año 2006, que se vio un fuerte abuso de los recuerdos de la sociedad para desprestigiar a un partido político. En esta ocasión, fue el ALN -Alianza Liberal Nicaragüense-, que por medio de su candidato Eduardo Montealegre dio paso a este tipo de propaganda política. En los spots publicitarios, se hacía alusión a que si ganaba el FSLN -Frente Sandinista de Liberación Nacional-, volveríamos a la crisis económica de la década

\footnotetext{
${ }^{1}$ El, Güegüense es una obra histórico-literaria de carácter anónimo del siglo XVII, calificada también como teatro de protesta contra el régimen colonial español donde se ridiculiza al segmento peninsular y la cúpula indígena de la sociedad colonial del momento.
} 
de los 80, regresarían los racionamientos alimenticios y por tanto las filas que se hacían para ingresar a los supermercados y comprar lo indicado.

Esa realidad que quiso plasmarse a través de la propaganda política, representa tan sólo una apreciación subjetiva de lo acontecido, pues es claro que quiso, mostrar quelas dificultades sociales fueron única y exclusivamente responsabilidad de la administración de ese momento. Pero, ¿por qué no mostrar los logros alcanzados en salud, educación y la Reforma Agraria alcanzadas por el pueblo en esa década? Debe recordarse que la Revolución Popular Sandinista como proyecto político, económico y social sustituyó a un régimen adverso para la mayoría de la población, especialmente a los sectores sociales más bajos, entonces ¿por qué no resaltar el intento de romper con tanta desigualdad y tantos males que acarreaban más de cuarenta años de dictadura dinástica?, o es que acaso ¿fue todo bonanza en el somocismo?

Ciertamente, debe reconocerse, que hasta inicios de la década del 70, Nicaragua gozó de estabilidad macroeconómica, y que en alguna medida esta se reflejaba en el modo de vivir de la sociedad. Pero, ya desde años atrás, la sociedad manifestaba su descontento hacia la ninguna apertura de libertades políticas. Esto se incrementó, cuando sobrevino la crisis petrolera a inicios del decenio señalado y que tuvo efectos devastadores en las economías latinoamericanas, especialmente a la pequeña Nicaragua. A esto, hay que sumar el terremoto de 1972, que puso al descubierto la voracidad de la Dictadura y de sus allegados al acaparar la mayor parte de la ayuda económica internacional generosamente brindada. Desde esta crisis económica y social, el régimen de los Somoza no volvió a levantar cabeza.

El malestar social era expresado por los sectores de la sociedad, entre ellos la Universidad. Los murales fueron símbolos de esta oposición y resistencia social, y se perpetuaron en el tiempo preservando dentro de sí y para las generaciones futuras - de hoy-atestiguando lo intenso de aquella lucha, el fuerte sentido de colectividad social de la universidad y el espíritu de vanguardia en problemas que afecten a la población. 


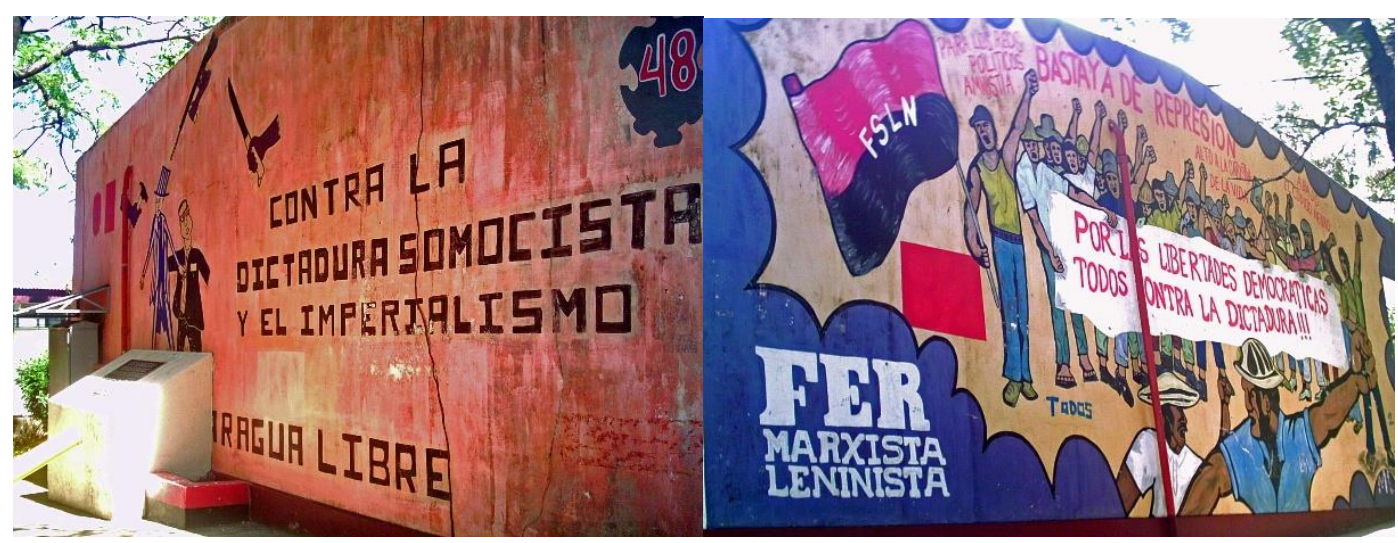

Los murales de la década del 70, se puede afirmar que son muestras de la juventud que luchaba y denunciaba todos los abusos cometidos contra el pueblo por la Dictadura Militar Somocista. Uno de los hechos repudiables cometidos contra la comunidad universitaria fue la masacre de 1959 en León, donde murieron 4 estudiantes de esa alma máter, lo cual constituyó un factor determinante para que estudiantes, maestros y trabajadores administrativos tomaran conciencia en la lucha contra Somoza, pues tanto la Universidad en su calidad de institución como sus miembros no se encontraban ajenos a esta realidad.

Posteriormente, el RURD, fue intervenido en múltiples ocasiones, la de mayor impacto fue en febrero de 1978, cuando la Guardia Nacional hizo un operativo y mató a dos estudiantes en los predios del recinto. La Universidad vino a ser uno de los ejes de las luchas populares, pues estudiantes, maestros y trabajadores administrativos participaron activamente en el derrocamiento de la dictadura. (Lobato et.al, 2006: 92)

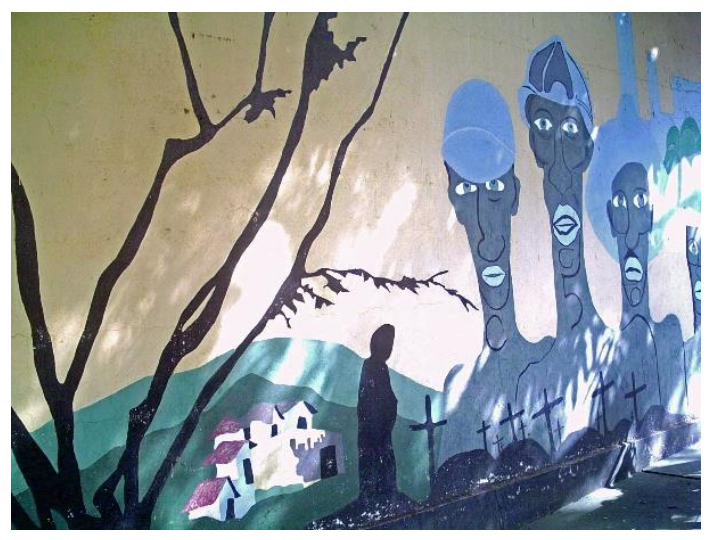

La utilización de tanques Sherman y los bombardeos aéreos, personas encarceladas, fusiladas, desaparecidas, la persecución hacia los jóvenes y el exilio de nicaragüenses huyendo de la muerte provocaron que México, Panamá, Colombia y Venezuela en la sede de la ONU condenaran el genocidio llevado a cabo por Somoza. Todo esto, era vivamente reflejado en los murales, pues estudiantes y maestros estaban de lleno involucrados en la situación del momento. En la década de los 70, la Universidad mantuvo una actitud crítica frente a la situación, y los gremios manifestaron un repudio total a la realidad existente en Nicaragua. 
Con el desplome de la Dictadura en julio de 1979, la tónica muralista cambió, pues ya se había conseguido uno de los objetivos que fue la caída de Anastasio Somoza Debayle, ahora el nuevo reto era defender el triunfo de la Revolución Popular Sandinista, era preciso pues, seguir incidiendo en la juventud más próxima, así como salvaguardar los mecanismos que la Revolución tenía para sostenerse en pie frente a las agresiones externas, un ejemplo de dichas herramientas fue el Servicio Militar Patriótico (1983), pues aunque unos asistían de forma voluntaria, otros se veían obligados por la ley, así fue necesario crear murales alusivos con el fin persuadir a las juventud y a la sociedad en general para apoyar al gobierno en la defensa de la soberanía. En este sentido, los murales fungen entonces como propaganda y difusión de políticas de gobierno y de la sociedad.

Hasta hace unos años, el tema de la guerra ha sido tan distorsionado a causa de la ignorancia provocada, que las alianzas políticas opuestas al FSLN, utilizan el recuerdo de la confrontación para fines electorales. En las elecciones presidenciales de 1996, 2000 y 2006 el fantasma del enfrentamiento entre hermanos nicaragüenses volvió a reaparecer, en los spot publicitarios se aludía a que si ganaba el Frente Sandinista la guerra iba a volver, que los talibanes se iban a apoderar del país, el testimonio de madres de hijos caídos en la conflagración fue manipulado, haciendo parecer que todo eso fue culpa de tal gobernante o en último caso de la Revolución.

Y es que la oposición interna y externa, ha incidido en darle el carácter de guerra civil al enfrentamiento que vivieron los nicaragüenses en los años 80 , y en cierta medida lo han logrado, pues la población no percibe la mano que se encontraba detrás de todo esto. La pretendida guerra civil no era más que una guerra de agresión. Por estos años, “el Estado Nicaragüense, demandó ante la Corte Internacional de Justicia en La Haya a los Estados Unidos, resultando una sentencia condenatoria para estos últimos, instándolos a pagar 17 mil millones de dólares por la agresión, deuda que fue perdonada por el gobierno neoliberal de Violeta Barrios de Chamorro.” (Avilés, 2006, p. 37)

En el ámbito universitario, estos hechos eran presentados tal cual eran, las políticas de defensa del Estado debían ser difundidas en todos los ámbitos, con el fin de que la sociedad en general y sobre todo aquella que podía ser más fácilmente influenciada por los sectores opositores a la Revolución, así en la medida en que los estudiantes se apropiaran de ese sentido de salvaguardar los logros alcanzados, en esa misma medida podían transmitirlos en su casa y en sus barrios. Así, la Universidad, cuyos maestros, trabajadores administrativos y estudiantes habían sido 
parte en la lucha contra la dictadura presentaba un ambiente propicio para la propagación de las ideas de defensa y consolidación del Estado Revolucionario.

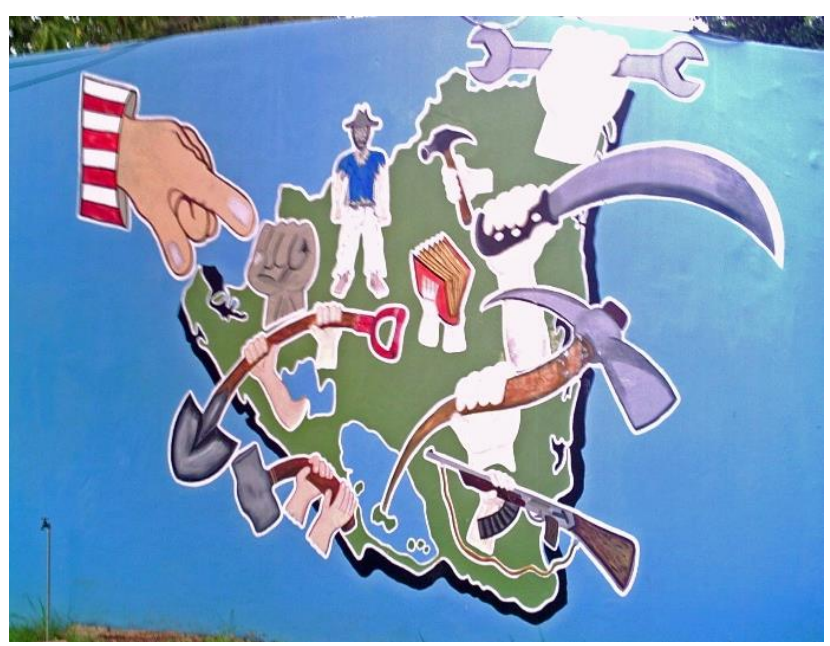

Obsérvese, lo que nos indica este mural: una Nicaragua revolucionaria a la vista de la omnipresencia del Tío Sam, pero presta a ser defendida por la población, así encontramos un pueblo en armas para defender su proceso, un pueblo libre del analfabetismo del que se encontraba sumido en el somocismo y un pueblo trabajador y a sobrellevar la crisis económica que tuvo como principales causas la guerra de agresión y el bloqueo económico.

De igual forma era justo y necesario perpetuar en el tiempo la gesta de la Cruzada Nacional de Alfabetización (CNA), para ello se pintó un mural en el Auditorio 12, compuesto de tres partes; la primera expresa el triunfo de la Revolución; la segunda refleja ruptura las cadenas que mantenían atada a la población durante la Dictadura Militar y la tercera representa la Cruzada Nacional de Alfabetización.

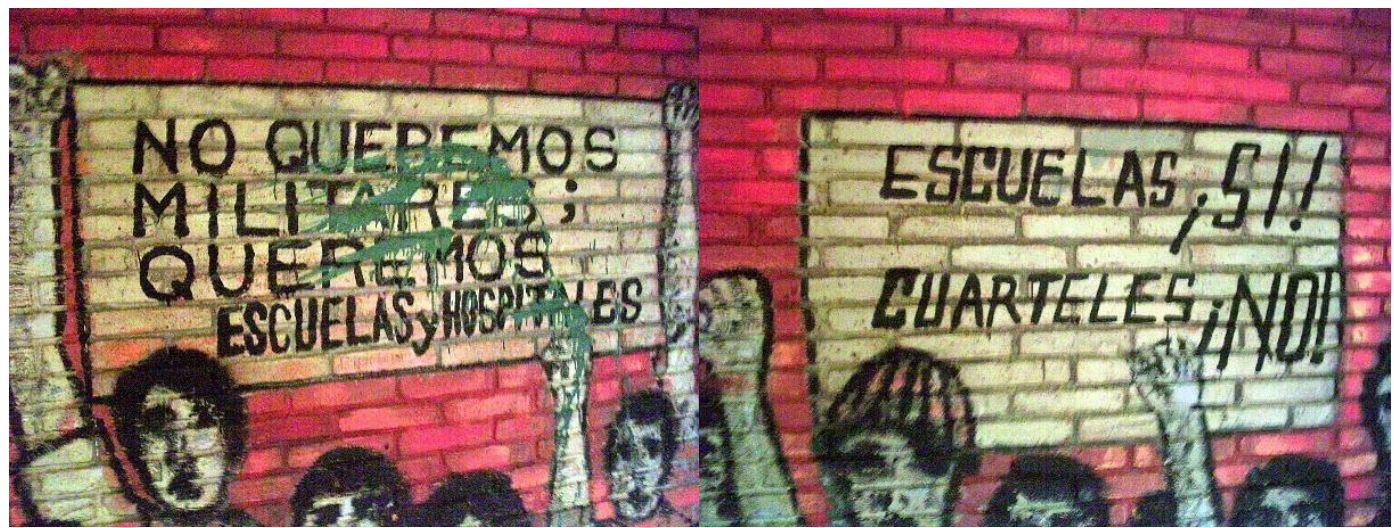

Entonces, ¿por qué los sectores políticos de derecha olvidan estos hechos y sólo difunden aquello que marcó el dolor de la población? ¿Por qué no decir, que en toda esa bonanza económica del somocismo, el pueblo vivía sumido en el analfabetismo o que padecía un sinnúmero de enfermedades sin que el Estado hiciera nada por erradicarlas? ¿Por qué no recordar la represión? Los murales arriba expuestos son muestra del rechazo a la militarización y a la carencia de servicios 
básicos por parte de la población, "con más del 50\% de la población sin saber leer y escribir, la gran Cruzada de 1980, redujo a tan sólo $12 \%$ el índice de analfabetismo, a través de los Comités de Defensa Sandinista, se logró en 1982, la erradicación total de la poliomielitis y el control de enfermedades como la tos ferina y el sarampión." (Avilés, 2006, p. 22)

Igualmente, se hizo uso de símbolos continentales, para impregnar en la población el sentido de defensa y la expansión de la Revolución, uno de estos símbolos fue el Che Guevara, conocido por su trayectoria internacionalista, propulsor de la Revolución Cubana en África, Bolivia, entre otros.

Al perder el poder el gobierno Sandinista, en 1990, se inició un nuevo contexto en la sociedad nicaraguiense y también en la Universidad, a partir de esta fecha hasta la actualidad, la elaboración de murales proliferó en todo el Recinto. Aún hoy se encuentran los murales con el fin de que las nuevas generaciones de jóvenes valoren el proceso vivido, pero hay un impedimento para ello. La mayoría de los estudiantes pasan delante de ellos sin ningún reparo ¿Por qué?

Con la derrota electoral del FLSN, los sectores que emergieron pretendieron empezar de cero, y en determinados aspectos lo lograron, sobre todo en el educativo, pues se cambiaron los planes de estudio de historia de la enseñanza primaria y media, reduciendo el conocimiento de los años 80 a una mera continuación de la época somocista, con lo que se logró borrar esa memoria de la juventud de hoy.

Con la Reforma Curricular de 1993, la materia de Historia solo se impartía de primero a tercer año, de los cuales sólo en el primer año se estudiaba la Historia de Nicaragua con estudiantes que oscilaban entre los 11 y 12 años, en los siguientes se impartía Historia de América y Universal respectivamente. Esta reforma se mantuvo hasta el año 2000, es decir, que todos aquellos nacidos en los años 80, que dada su edad no recordaban nada acerca del proceso revolucionario, y que transitaron las escuelas del Estado en toda la década del 90 quedaron sin memoria alguna respecto a lo acontecido en la década anterior, además ¿qué grado de aprehensión puede tener un niño de la edad señalada cuando se abordan procesos históricos tan polémicos?

De ahí la necesidad de fortalecer la identidad que había caracterizado a la universidad desde los años 70, para de esta manera incidir en la juventud y tratar de devolverle esa memoria que le había sido borrada en su enseñanza secundaria. Entonces, “...fue necesario traer del olvido y rescatar aquellos personajes y grandes hombres que fueron símbolo para la comunidad 
universitaria, cuando se luchaba contra la Dictadura y que significaban mucho para el ser social de la universidad" (Entrevista a Rolando Mendoza, realizada el 27 de noviembre, 2006). Con este interés, los gremios universitarios dieron la pauta a que se pintaran murales de Augusto C. Sandino, Rigoberto López Pérez, Ricardo Morales Avilés, Carlos Fonseca Amador y Luis Felipe Mondada, éstos en cuanto a se refiere a héroes y mártires. ${ }^{2}$
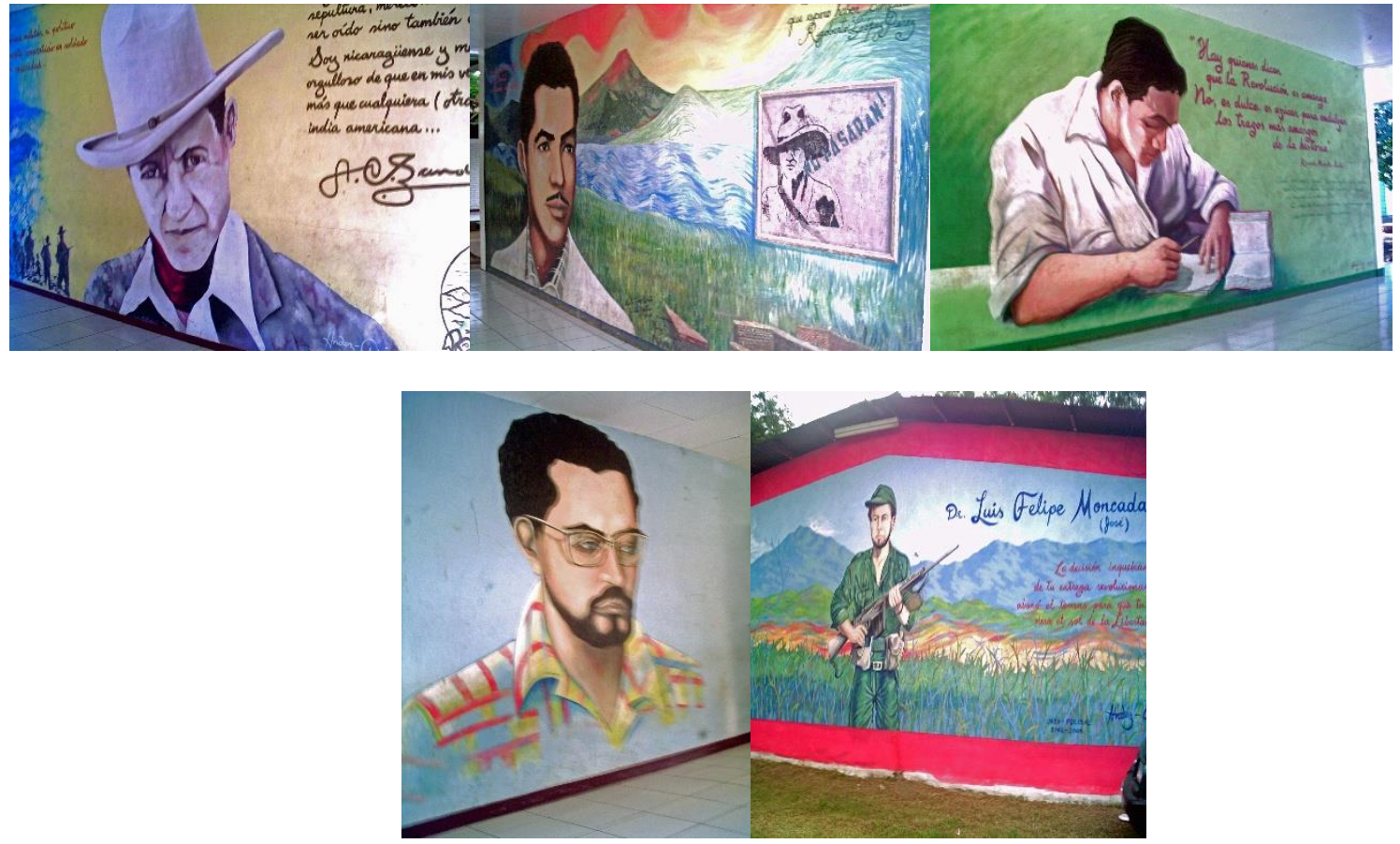

Por su parte, el gremio de docentes promovió el mural dedicado a Esperanza Monje guerrillera en los 70, trabajadora incansable de la universidad en los años 80 y que pese a sus limitaciones logró licenciarse en Psicología, y llegó a ser secretaria del sindicato Asociación de Trabajadores Docentes ATD, luego murió en un accidente de tránsito en 1992. Era necesario transmitir a la juventud que estos hombres y mujeres habían pasado a la historia por sus valores y virtudes.

\footnotetext{
${ }^{2}$ Augusto Calderón Sandino, es el héroe que defendió la soberanía nacional en tiempos de la segunda intervención militar norteamericana 1926-1933 y que fue asesinado por órdenes de Anastasio Somoza García en 1934, sometiendo su figura al olvido. Luego en los años 60, y bajo sus ideales se funda el FSLN. Rigoberto López Pérez, fue el que dio inicio al fin de la Dictadura, cuando en septiembre de 1956 dio muerte en un acto público a Somoza García, acción que le costó la vida al momento. Ricardo Morales Avilés, uno de los dirigentes del FSLN, cae en combate el 18 de septiembre en Nandaime. Carlos Fonseca Amador, fue uno de los fundadores del FSLN a inicios de la década del 60 y uno de los Comandantes de la Revolución, cayó combatiendo el 8 de noviembre de 1976 en Zinica. Luis Felipe Moncada, dirigente del Frente Oriental Jacinto Hernández muere en combate el 17 de mayo de 1979.
} 


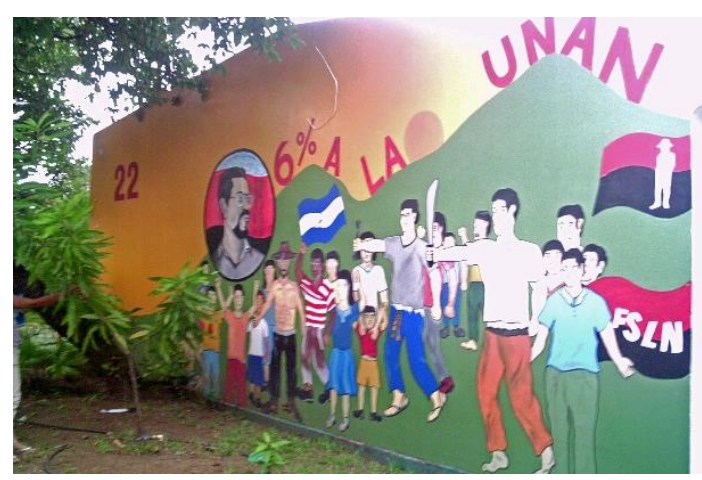

En los últimos años, la comunidad universitaria en general, tuvo que hacer frente al peligro de que los recuerdos de sus sufrimientos, triunfos de la Revolución y sus luchas por el $6 \%^{3}$ de las universidades, fueran olvidados o borrados de la memoria colectiva por las medidas tomadas por los gobiernos neoliberales que se instalaron a partir de 1990.Nótese, en este último mural, la vinculación de una necesidad social -la educación superiorcon una fuerza política, donde a la vez se retoman dos figuras de la Revolución -Augusto C. Sandino y Carlos Fonseca-, esto se debe en primera instancia a que la aprobación de la Ley de Autonomía Universitaria y del 6\% constitucional, partieron de iniciativas del Frente Sandinista, el cual en estos años de neoliberalismo ha estado apoyando dicha necesidad social, contrario a las bancadas de tendencia liberal.

\section{A modo de conclusiones.}

Para terminar este ensayo, hemos querido dejar para este momento, una de las preguntas claves del tema: ¿Qué experiencias del pasado están en el presente?, es decir, en la juventud de hoy. Queda claro que las personas de mayor edad que fueron partícipes de las luchas de las décadas de los 60 y 70, aún guardan en su memoria el recuerdo de aquellos años cuando por todos los medios se expresaba el rechazo a la Dictadura Militar Somocista, a la vez que conservan vivos los triunfos alcanzados con la Revolución Popular Sandinista, referidos a salud y educación, incluyendo en ello la Cruzada Nacional de Alfabetización.

Por eso, retomando la pregunta antes señalada, es preciso retomar el cercenamiento de la memoria que sufre la juventud de hoy, como herencia de su enseñanza primaria y media. La mayoría de la juventud, desconoce el significado o lo que representan todos estos héroes y mártires, a los sumo recuerdan a Sandino y al Che Guevara como únicos símbolos de lucha nacional e internacional. En este sentido, batallar y recuperar la memoria, no se limita a hacer uso de tales símbolos en las camisetas, sino, ahondar en el significado histórico-social de esos personajes, además, ¿de qué sirve que estén los murales si la población estudiantil no sabe lo que significan? Es por ello, que debemos de insistir en que el lenguaje de los murales sea entendido, que su mensaje

\footnotetext{
${ }^{3}$ Hace alusión al porcentaje de dinero que del presupuesto general de la nación debe ser entregado a las universidades públicas y que en virtud de la Ley 89 o de Autonomía Universitaria administran personalmente.
} 
sea transmitido y a la vez recuperar del olvido las diversas voces, las diferentes expresiones de un pasado común con fuerte incidencia en nuestro tiempo.

Es preciso, incidir en juventud, trayendo al presente símbolos de luchas sociales, personas emblemáticas que en su tiempo protestaron por el bienestar, los derechos de la población y contribuir al fortalecimiento de la memoria histórica institucional.

Para finalizar, debe destacarse el valor cultural e identitario de los murales y su potencial como fuente iconográfica de la Historia, que estudia la dinámica de la sociedad. Es importante señalar que, mientras algunos han sido restaurados, otros están en un estado de deterioro progresivo, sin que se haga nada para remediarlo, es común ver entre ellos como el comején, divide las pinturas dañando los colores, o como el tiempo, el sol, la lluvia se llevan consigo la memoria preservada en estos, y por tanto la experiencia, y la historia vivida por nuestra sociedad.

\section{REFERENCIAS}

Amador, Armando. (1992) Un siglo de lucha de los trabajadores de Nicaragua (1880-1979). Managua: Universidad Centroamericana.

Antognazzi, Irma. Comp. (2006) Historia y memoria colectiva: dos polos de una unidad. Argentina: Universidad Nacional de Rosario.

Avilés Salmerón, Ricardo. (2006) "Breves apuntes sobre la Revolución Popular Sandinista", en material de lecturas del curso Problemas de la Historia de las Sociedades del Pacífico y Atlántico de Nicaragua de la Maestría en Estudios Históricos Latinoamericanos y del Caribe. Managua: UNAN.

Lobato Blanco, Luis. Et.al. (2006) "La UNAN-Managua y su historia. Parte I." en Revista de Historia y Ciencias Sociales. No. 8. Departamento de Historia, Managua: UNAN-Managua.

Lobato Blanco, Luis-Franco Fredy. (2006) “Auge de la Universidad y desarrollo de la UNANManagua, desde la década de los ochenta hasta la actualidad. (II parte)." En Revista de Historia y Ciencias Sociales. No. 9. Departamento de Historia. Managua: UNAN-Managua. Meyer Eugenia. (2000) “Transmisión de la conciencia histórica. Memoria y conciencia histórica”, en Revista de Historia, Antropología y Fuentes Orales. No. 24. Recordar el olvido. España: Universidad de Barcelona. 
Meyer, Eugenia. (1998) “Desconstrucción de la memoria, construcción de la historia”. En Revista de Historia, Antropología y Fuentes Orales. No 19. Más allá de la imagen. España. Universidad de Barcelona.

Rosenzviag, Eduardo. (1998) "Vida, muerte y resurrección de las chimeneas en la memoria oral", en Historia, Antropología y Fuente Oral. No. 20. Traumas del siglo XX., España: Universidad de Barcelona.

Varios Autores. (2007) Memorias de una ciudad. Las imágenes y los testimonios como recurso para descubrirlas. Ponencia presentada al II Encuentro Internacional de Historia Oral. Panamá, 29 de enero-de de febrero del 2007. 